\title{
Role of the prophylactic fixation of contralateral unaffected hip in paediatric unilateral slipped capital femoral epiphysis: a systematic review
}

\author{
Filippo Maria Anghilieri ${ }^{1}$, Ilaria Morelli², Giuseppe M Peretti ${ }^{3,4}$, Fabio Verdoni ${ }^{3}$ \\ and Domenico Curci ${ }^{3}$ \\ ${ }^{1}$ Residency Program in Orthopaedics and Traumatology, School of Medicine and Surgery, University of Milan, \\ Milan, Italy \\ ${ }^{2}$ U.O.C. Ortopedia e Traumatologia, ASST Ovest Milanese, Nuovo Ospedale di Legnano, Legnano, Milano, Italy \\ ${ }^{3}$ IRCCS Istituto Ortopedico Galeazzi, Milan, Italy \\ ${ }^{4}$ Department of Biomedical Sciences for Health, University of Milan, Milan, Italy
}

\author{
Correspondence \\ should be addressed \\ to I Morelli \\ Email \\ ilaria.morelli90@gmail.com
}

- The aim of this systematic review is to assess the role of the prophylactic fixation of contralateral unaffected hip in unilateral slipped capital femoral epiphysis (SCFE) in children, focusing on the possible complications of this surgical procedure.

- A systematic review of medical literature was conducted, according to the Preferred Reporting Items for Systematic review and Meta-Analysis (PRISMA) statement, to analyse the complications of prophylactic contralateral hip fixation in unilateral paediatric SCFE. We registered the complications reported in the included studies, scoring their severity according to the orthopaedic adaptation of Clavien-Dindo classification.

- From 1695 studies primarily identified, 14 studies were finally included: 1 prospective cohort study, 4 retrospective case-control studies and 9 retrospective case series, with a total of 811 children diagnosed with unilateral SCFE and treated on the unaffected contralateral hip. Grade IV complications were very rare $(0.37 \%)$, while the rate of grade III events was $8 \%$. No death was recorded. The most frequent complication was unplanned further surgery (6.29\%) that was an epiphyseal refixation, owing to the physiologic growth of the proximal femur, in 42 cases. Cannulated screws fixation showed to have a lower major complication rate than pinning with K-wires, $5.37 \%$ vs $17.95 \%$.

- The prophylactic fixation of contralateral unaffected hip in paediatric unilateral SCFE is a safe procedure. Although a benefit-cost analysis on this topic has not been published yet, considering the low rate of complications, prophylactic hip fixation is a viable option for patients presenting with unilateral SCFE, to prevent the occurrence of severe hip deformity and avoid future invasive surgeries.

\section{Keywords}

- epiphysiolysis

- paediatric orthopaedics

- slipped capital femoral epiphysis

- prophylactic surgery

- prophylactic fixation

- bone screws

$\checkmark$ child

- systematic review

\section{Introduction}

Slipped capital femoral epiphysis (SCFE) is defined as the posteroinferior displacement of the proximal femoral epiphysis from the metaphysis. To date, SCFE is one of the commonest developmental orthopaedic diseases, affecting from 0.2 to 10 per 100000 children worldwide $(1,2)$. Furthermore, its incidence appears to be slightly increasing in many world regions, likely due to changes in childhood obesity prevalence (3). Indeed, several risk factors have been identified, including obesity, ethnicity, modified Oxford bone age score, renal failure, endocrinopathies but, above all, hypothyroidism and growth hormone deficiency $(4,5,6,7,8)$.

The prevalence of bilateral SCFE is highly variable and ranges between 20 and $80 \%(9,10)$; in approximately $50 \%$ of cases, a simultaneous bilateral slip occur (11). According to Novais et al, contralateral SCFE occurs mostly within a year from the first slip (10).

The remaining $50 \%$ of patients develop an asynchronous contralateral slip, in $82 \%$ of cases within 18 months from the initial slip (12). Unluckily, during 
childhood and adolescence, the contralateral slip is often underdiagnosed. A 30-year follow-up study on patients with unilateral SCFE showed radiographic features of undiagnosed contralateral slip in $40 \%$ of patients (13).

The gold standard treatment for mild SCFE is the in situ surgical fixation of the slipped femoral head (14). No consensus exists not only on the best treatment for moderate-to-severe stable and unstable SCFE but also on the best hardware to be used for in situ fixation (14). Screw fixation is associated with a slight increase in premature physis closure, compared to K-wires fixation, in some studies. As a consequence, even if the most recent literature favours the use of screws, some authors instead advocate the use of k-wire pinning in younger patients, because of the reduced rate of adverse events on femoral neck growth $(14,15,16)$. On the other hand, K-wires have a higher risk of migration, due to their less effective anchoring in bones (17).

Nevertheless, the main controversy concerns the prophylactic fixation of the unaffected normal-appearing hip $(18,19,20,21,22)$.

In fact, children presenting with unilateral SCFE are reported to have a 2335 times greater risk of developing a subsequent contralateral slip than a child in the general population (21). Therefore, some authors advocate prophylactic fixation stressing the benefits of preventing a subsequent contralateral slip with a minimally invasive procedure $(23,24,25)$. Other authors instead reject the indication for this surgical procedure in all patients because of the risk of harming a potential healthy hip $(26,27,28,29)$.

The purpose of this review was to summarize the published evidence regarding safety and potential complications of the surgical techniques used for prophylactic fixation of the unaffected contralateral hip in unilateral SCFE.

\section{Materials and methods}

\section{Focused question based}

Based on the Preferred Reporting Items for Systematic review and Meta-Analysis (PRISMA) guidelines (30), specific questions were constructed. The focused questions addressed were "What are the safety and possible complications of prophylactic fixation of the contralateral hip in unilateral SCFE in children?' and 'Are there any differences in the complication rates between the surgical techniques described?'

\section{Eligibility criteria}

All the following criteria had to be satisfied to determine study eligibility: (i) original clinical studies and case series (ii) written in English, (iii) including a minimum of five patients, (iv) younger than 18 years of age and ( $v$ ) affected by unilateral SCFE and treated with contralateral hip prophylactic fixation.

Letters to the editor, reviews, editorials, case reports and unpublished articles were excluded.

\section{Search strategy and study selection}

We conducted a comprehensive literature search using PubMed/Medline (National Library of Medicine, Washington, DC) and Scopus (Elsevier API) from 1 January1990 to 31 March2021, since the first reports of prophylactic fixation date back to the early 1990 s $(31,32)$. The following string was used to perform the literature search: ('epiphysiolysis' OR 'slipped capital femoral epiphysis' OR 'SCFE') AND ('management' OR 'treatment' $O R$ 'surgery' OR 'fixation' OR 'screw').

After duplicates removal, the titles and abstracts of the identified articles were screened by two independent reviewers (FMA and IM) and checked for agreement. Disagreement was solved through debate, involving the other authors. The studies included during the screening phase were read in full and evaluated based on the stated eligibility criteria. Reference lists of potentially relevant original articles were hand-searched to identify any remaining study, unidentified in the previous steps. Once again, the articles were checked for agreement among the authors (Fig. 1).

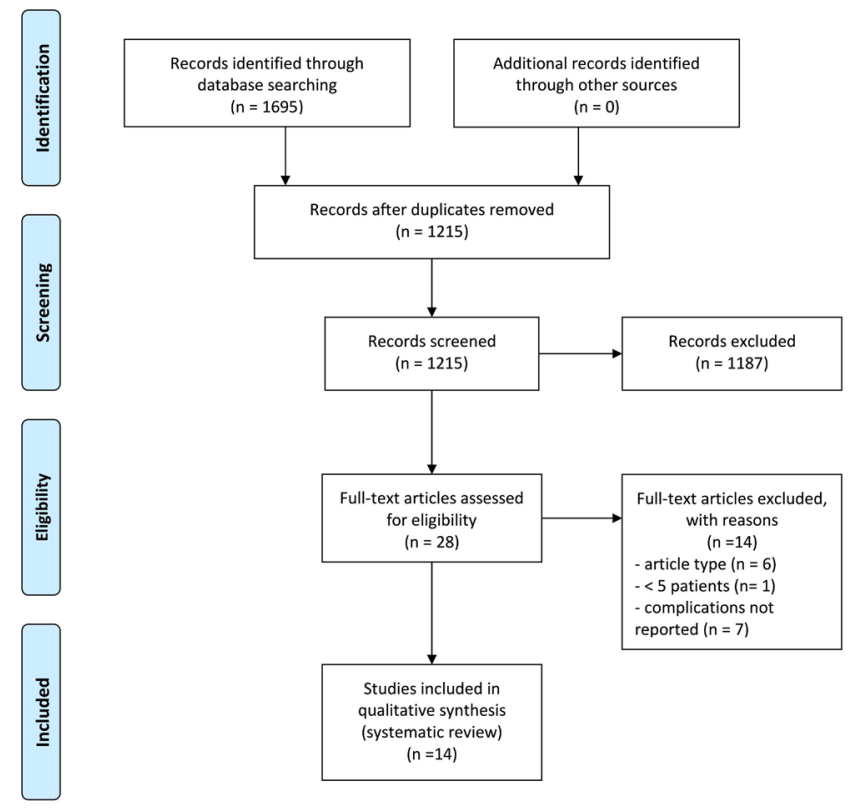

Figure 1

PRISMA flow chart. 


\section{Methodological study quality assessment and data extraction}

The Methodological Index for Non-randomized Studies (MINORS) scoring system was used to assess the quality of each study included (33).

The revised and validated version of MINORS includes eight methodological items for non-comparative studies: (i) clearly stated aim, (ii) inclusion of consecutive patients, (iii) prospective collection of data, (iv) endpoints appropriate to the aim of the study, (v) unbiased assessment of the study endpoint, (vi) follow-up period appropriate to the study aim, (vii) loss to follow-up $<5 \%$ and (viii) prospective calculation of the study size.

To score comparative studies, the MINORS system provides four additional items as follows: (ix) adequate control group, $(x)$ contemporary groups, (xi) baseline equivalence of groups and (xii) adequate statistical analyses.

The items are scored 0 (not reported), 1 (reported but inadequate) or 2 (reported and adequate), and the global ideal score being 16 for non-comparative studies and 24 for comparative studies.

According to MINORS, the study quality was considered high only when an article reached full scores (16/16 for non-comparative studies and 24/24 for comparative ones) and low in all other cases.

From the included articles, the following data were considered relevant to this review: article type, journal, year of publication, presence of a control group, number of patients and hips included, sex, mean age, follow-up period, surgical techniques, peri-operative and postoperative complications.

\section{Classification of surgical complications}

We classified the post-surgical complications recorded in the selected studies according to a recent orthopaedic adaptation (34) of the validated Clavien-Dindo classification (35). Grade $V$ is assigned for the death of the patient; grade IV for a complication that is life/limb-threatening, requires admission in an intensive care unit (ICU), is not treatable with potential permanent disability or that requires organ resection (total hip arthroplasty); grade III for a complication that is treatable but requires further intervention or unplanned hospital readmission; grade II for alteration of normal course and grade I for any complication that requires no treatment and has no clinical relevance.

With regards to SCFE, we considered avascular necrosis (AVN) of the femoral head and chondrolysis as grade IV complications and fractures, deep infections, hardwarerelated pain requiring removal and other unplanned surgery (including pin replacement or subsequent arthroscopic or open hip surgeries) as grade III complications. Grade IV to grade III events, for the fact of deeply deviating the post-surgical canonical course, were considered as major complications, while grade $V$ events were considered fatal complications.

Grade II, in the end, was assigned to complications like superficial infections, hardware-related pain not requiring removal, keloid scars, pin penetration and any complication during pin removal. We defined minor complications of all the events listed in Clavien-Dindo classification grades I and II.

\section{Results}

\section{Literature search and quality assessment}

The initial search yielded 1695 studies. After duplicates removal, 1215 articles were screened for eligibility and 1187 studies, which did not fulfil the eligibility criteria, were excluded (Fig. 1). In total, 14 studies were included and processed for data extraction $(31,32,36,37,38,39$, $40,41,42,43,44,45,46,47)$. For the nine case series included, the mean MINORS score was 9 out of 16 (ranging from 6 to 11), whereas for the five comparative studies, the mean MINORS score was 15 out of 24 (ranging from 12 to 19) (Table 1). Concerning the adequacy of follow-up, in the present review, 1 point was assigned for follow-up $<5$ years, while 2 points were assigned

Table 1 References, MINORS score and type of study for each article included.

\begin{tabular}{lcc}
\hline Reference & & MINORS score \\
\cline { 1 - 2 } Emery et al. (31) & $9 / 16$ \\
Rumm et al. (44) & $11 / 16$ \\
Seller et al. (47) & $13 / 24$ \\
Dewnany et al. (43) & $7 / 16$ \\
MacLean et al. (42) & $12 / 16$ \\
Breaud et al. (41) & $12 / 24$ \\
Woelfle et al. (46) & $6 / 16$ \\
Sankar et al. (40) & $8 / 16$ \\
Vlachopoulos et al. (39) & $9 / 16$ \\
Clement et al. (38) & $8 / 16$ \\
Bhattacharjee et al. (37) & $16 / 24$ \\
Herngren et al. (36) & $15 / 24$ \\
Lerch et al. (45) & $19 / 24$ \\
& $8 / 16$
\end{tabular}

\begin{tabular}{l} 
Study design \\
\hline Retrospective case series \\
Retrospective case series \\
Retrospective case-control \\
Retrospective case series \\
Retrospective case series \\
Retrospective case-control \\
Retrospective case series \\
Retrospective case series \\
Retrospective case series \\
Retrospective case series \\
Retrospective case-control \\
Retrospective case-control \\
Prospective cohort study \\
Retrospective case series
\end{tabular}

\begin{tabular}{l}
\hline Control group \\
\hline None \\
None \\
Clinical/radiographic observation \\
None \\
None \\
Clinical/radiographic observation \\
None \\
None \\
None \\
None \\
Clinical/radiographic observation \\
Clinical/radiographic observation \\
Clinical/radiographic observation \\
None
\end{tabular}


for follow-up $\geq 5$ years. This decision was based on the fact that we considered fully appropriate follow-up that reached the period of physeal closure and therefore the end of bone growth. Only four studies were scored $2 / 2$ for the follow-up period $(32,43,44,45)$. A prospective calculation of sample size was absent in all the included studies. According to MINORS score, the quality of all included studies was considered low.

\section{General characteristics of included studies}

No randomized-controlled trials were found to be included in this review. We included one prospective cohort study, four retrospective case-control studies and nine retrospective case series (Table 1). Altogether, the 14 studies included in this review counted 811 children diagnosed with unilateral SCFE and treated with prophylactic fixation of the unaffected contralateral hip. Three studies $(45,46$, 47) reported the surgical technique of pinning by means of K-wires (a total of 195 patients), while ten studies (31, $32,36,37,38,39,40,41,42,43,44)$ were based on the use of cannulated screws (521 patients). In the study by Emery et al. (31), the chosen implants were Crawford and Adams pins (95 hips treated) (Table 2).

The mean age in the population of the current review, weighted on the eight studies in which it is assessed, was 12.5 years old. Coherently with literature, male sex was prevalent, representing $59 \%$ of the total (10 studies out of 14 reported sex distinction). The cumulative mean period of follow-up was 54.28 months (4.5 years), with an extreme value of 12 years for the 36 patients reported by Lerch et al. (45).

\section{Complications rate}

The overall reported complications rate according to the orthopaedic adaptation of Clavien-Dindo classification are summarized in Table 3.
No case of death was registered following prophylactic fixation in the studies included in this review; therefore, no grade $V$ complications were found. No case of chondrolysis was referred, while two studies $(32,40)$ reported the occurrence of AVN. Roustocher et al. (32) reported 1 patient out of 51 (2\%) and Sankar et al (40) 2 patients out of 99 (2\%) who experienced this adverse event after prophylactic fixation surgery. Only 3 out of 811 patients included in this systematic review were affected by grade IV complications ( $0.37 \%)$.

Four patients sustained femoral fractures, 1 patient had a deep infection, 9 patients complained of pain requiring implant removal and 51 patients needed further surgery that had not been planned at the time of prophylactic fixation $(31,36,37,39,40,44,45,46,47)$. The cumulative rate of grade III complications was $8.01 \%$ (65 patients out of 811). The most represented complication of this class was unplanned further surgery: a total of 42 children underwent reoperation because the pin did not catch the epiphysis anymore owing to physiologic growth of the proximal femur, resulting in a loss of fixation. Lerch et al. (45) reported the need for a further intervention for a subsequent cam-type femoroacetabular impingement (FAl), treated in three cases through an open surgical approach and in one case arthroscopically (Table 4). A total of 51 children underwent further surgeries, not planned at the time of prophylactic fixation, with a cumulative rate in the present review of $6.29 \%$. Grade IV to grade III, jointly considered as major complications, are reported with cumulative rate of $8.38 \%$.

With regards to grade II complications, superficial infection of the surgical wound was reported in nine patients without consequences, while temporary implantrelated pain with no necessity of removal was registered in eight cases $(31,37,40,43,46)$. Other minor adverse events included in grade II class were recorded only in some studies and not all patients have been investigated

Table 2 First author, surgical hardware, number of hips, sex, mean age and duration of follow-up of the included articles.

Authors
Emery et al. (31)
Kumm et al. (44)
Rostoucher et al. (32)
Seller et al. (47)
Dewnany et al. (43)
MacLean et al. (42)
Breaud et al. (41)
Woelfle et al. (46)
Sankar et al. (40)
Vlachopoulos et al. (39)
Clement et al. (38)
Bhattacharjee et al. (37)
Herngren et al. (36)
Lerch et al. (45)

\begin{tabular}{l} 
Hardware \\
\hline Crawford Adams pins (2-4) \\
Dynamic screw \\
Single screw \\
3-4 K-wires \\
Single cannulated cancellous screw \\
Single cannulated screw \\
Single cannulated screw \\
3 K-wires \\
Single cannulated screw \\
Single cannulated cancellous screw \\
Single cannulated screw \\
Richards cannulated hip screw \\
Single screw \\
K-wires (mostly 2)
\end{tabular}

\begin{tabular}{|c|c|}
\hline \multicolumn{2}{|c|}{$\boldsymbol{n}$} \\
\hline Hips & Males \\
\hline 95 & 69 \\
\hline 34 & 17 \\
\hline 51 & $\mathrm{NA}$ \\
\hline 94 & $\mathrm{NA}$ \\
\hline 65 & 33 \\
\hline 17 & NA \\
\hline 13 & 12 \\
\hline 65 & 41 \\
\hline 99 & 55 \\
\hline 11 & 5 \\
\hline 36 & NA \\
\hline 44 & 24 \\
\hline 151 & 85 \\
\hline 36 & 21 \\
\hline
\end{tabular}

\begin{tabular}{|c|c|c|c|}
\hline \multicolumn{3}{|c|}{ Mean age in years } & \multirow[b]{2}{*}{ Follow-up, years } \\
\hline All & Males & Females & \\
\hline 13.7 & & & NA \\
\hline 12.7 & 13.5 & 11.9 & 5.4 \\
\hline NA & & & 6.5 \\
\hline NA & & & NA \\
\hline 12.5 & & & 6.5 \\
\hline NA & & & NA \\
\hline 13.7 & 13.8 & 12 & NA \\
\hline NA & & & 3.0 \\
\hline 11 & & & 2.7 \\
\hline 12.1 & 13.2 & 11.1 & 3.1 \\
\hline NA & & & NA \\
\hline 12.5 & & & NA \\
\hline NA & & & 3 \\
\hline 13 & & & 12 \\
\hline
\end{tabular}

NA, not assessed. 
Table 3 Overall reported complications rate in the included articles, according to Clavien-Dindo classification.

\begin{tabular}{|c|c|c|c|c|}
\hline \multirow[b]{2}{*}{ References } & \multicolumn{4}{|c|}{ Complications rates } \\
\hline & $\begin{array}{c}\text { Grade V } \\
(\%) \\
\end{array}$ & $\begin{array}{c}\text { Grade IV } \\
(\%)\end{array}$ & $\begin{array}{c}\text { Grade II } \\
(\%)\end{array}$ & $\begin{array}{c}\text { Grade II } \\
(\%)\end{array}$ \\
\hline Emery et al. (31) & $0(0)$ & $0(0)$ & $5(5.26)$ & $30^{\dagger}$ \\
\hline Kumm et al. (44) & $0(0)$ & $0(0)$ & $10(29.41)$ & $4(11.76)$ \\
\hline Rostoucher et al. (32) & $0(0)$ & $1(2)$ & $0(0)$ & $0(0)$ \\
\hline Seller et al. (47) & $0(0)$ & $0(0)$ & $16(16.5)$ & $0(0)$ \\
\hline Dewnany et al. (43) & $0(0)$ & $0(0)$ & $0(0)$ & $3(4.58)$ \\
\hline MacLean et al. (42) & $0(0)$ & $0(0)$ & $0(0)$ & $0(0)$ \\
\hline Breaud et al. (41) & $0(0)$ & $0(0)$ & $0(0)$ & $1(7.69)$ \\
\hline Woelfle et al. (46) & $0(0)$ & $0(0)$ & $11(16.92)$ & $2(3.1)$ \\
\hline Sankar et al. (40) & $0(0)$ & $2(2)$ & $4(4)$ & $1(1)$ \\
\hline Vlachopoulos et al. (39) & $0(0)$ & $0(0)$ & $2(18.2)$ & $0(0)$ \\
\hline Clement et al. (38) & $0(0)$ & $0(0)$ & $0(0)$ & $0(0)$ \\
\hline Bhattacharjee et al. (37) & $0(0)$ & $0(0)$ & $3(6.83)$ & $1(2.28)$ \\
\hline Herngren et al. (36) & $0(0)$ & $0(0)$ & $6(3.97)$ & $5^{\dagger}$ \\
\hline Lerch et al. (45) & $0(0)$ & $0(0)$ & $8(22)$ & $0(0)$ \\
\hline Total & $0(0)$ & $3(0.37)$ & $65(8.01)$ & $\mathbf{4 7}$ \\
\hline
\end{tabular}

†Single percentages in these cases are not added because they are calculated on different totals.

for them: 3 cases of keloidal scar, 9 cases of pin penetration and 18 cases of complications occurred during pins removal $(31,36,41,43,44)$. The latter was the most frequent complication of this class: Emery et al (31) found a rate of $5.6 \%$ (10 patients out of 64 ), Kumm et al. (44) $5.88 \%$ (2 patients out of 34 ), Breaud et al. (41) $7.69 \%$ (1 patient out of 13) and Herngren et al. (36) 9.8\% (5 patients out of 51).

\section{Kirschner wires vs cannulated screws}

We compared the complications rate in cases of prophylactic fixation obtained with cannulated screws to those using K-wires (Table 5). The study by Emery et al (31) was excluded from this analysis because the surgical procedure was performed with Adams-Crawford pins, not comparable with the other two hardware.

No case of chondrolysis following prophylactic pinning was reported. In our review, we registered 3 cases (0.58\%) of AVN in the 521 patients treated with screws and none in those treated with K-wires $(32,40)$. Furthermore, femur fractures and deep surgical wound infections were found only in the group of patients treated with screws: $0.77 \%$ ( 4 out of 521 ) and $0.19 \%$ ( 1 out of 521 ), respectively $(36,40)$.

Pain caused by the implant requiring hardware removal was found in both groups: $2.05 \%$ among patients treated with K-wires (4 out of 195) and $0.77 \%$ among those treated with screw fixation (4 out of 521$)(31,37,40,45)$.

The occurrence of unplanned surgery was the most frequent complication in the entire current systematic review. In the 'K-wires group', we found 31 patients recorded for this inconvenient (15.9\%), while in the 'screw group', there were only 16 cases $(3.07 \%)(31,36,37,39$, $44,45,46,47)$.

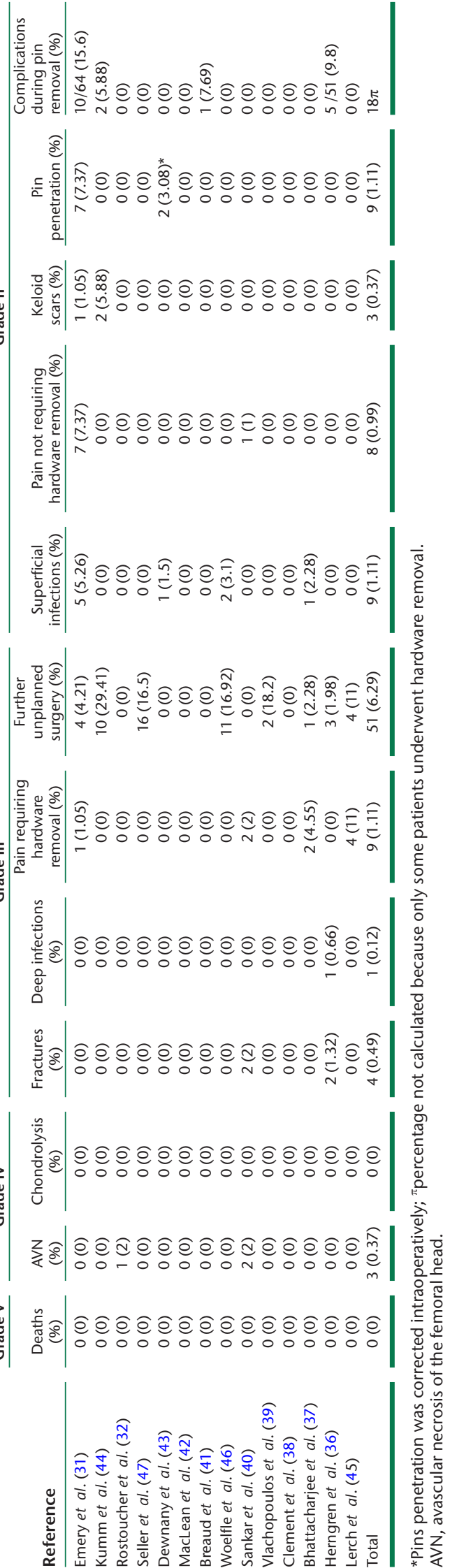


Table 5 Complications in patients treated with K-wires vs cannulated screw.

\begin{tabular}{|c|c|c|}
\hline Complications & K-wires & Screws \\
\hline Number of hips treated & 195 & 521 \\
\hline \multicolumn{3}{|l|}{ Grade IV } \\
\hline Chondrolysis & 0 & 0 \\
\hline AVN & 0 & 3 \\
\hline \multicolumn{3}{|l|}{ Grade III } \\
\hline Fractures & 0 & 4 \\
\hline Deep infections & 0 & 1 \\
\hline Pain requiring hardware removal & 4 & 4 \\
\hline Further unplanned surgery & 31 & 16 \\
\hline \multicolumn{3}{|l|}{ Grade II } \\
\hline Superficial infections & 2 & 2 \\
\hline Pain NOT requiring hardware removal & 0 & 1 \\
\hline Keloid scars & 0 & 2 \\
\hline Pin penetration & 0 & 2 \\
\hline Complications during pin removal & 0 & 8 \\
\hline Total in the review & $37(18.97 \%)$ & $43(8.25 \%)$ \\
\hline
\end{tabular}

AVN, avascular necrosis of the femoral head.

Cumulatively, in our review, we measured a rate of major complications (grades IV and III according to the orthopaedic adaptation of Clavien-Dindo classification) of $17.95 \%$ for the prophylactic fixation with K-wires and $5.37 \%$ for the surgery by means of cannulated screws.

\section{Discussion}

The fixation of the contralateral unaffected hip in paediatric unilateral SCFE is a prophylactic surgical procedure; therefore, its success stands in the non-occurrence of the adverse event it aims to prevent.

For this reason, we have chosen to evaluate its advantages by focusing our attention on the complications rate registered in modern literature. This is a contentious topic for the fact that, in case of intervention, there is a risk of harming a joint in a healthy starting condition, but, on the other hand, refraining from intervention puts the patient at risk of a disease that can lead to disability (48). Factually, untreated SCFE may result in progressive articular deformity and pain, impairment of the femoral epiphysis and limited range of motion of the hip joint (49). These complications represent an element of mediumterm disability for the child, deeply affecting his quality of life (50). Furthermore, they can have a negative impact on bone and stature development, requiring most invasive surgeries in the future (51). Proximal femoral osteotomies or joint prosthetic replacements in juvenile age are themselves technically challenging and guide the child to a future of multiple surgeries with increasing difficulties and potential complications $(52,53)$. In fact, up to $33 \%$ of the contralateral hips with a post-slip deformity develop radiographic features of juvenile osteoarthritis at follow-up ranging from 16 to 66 years $(13,28)$. It is debated that even mild SCFE deformities are able to lead to femoroacetabular impingement (FAl (54) and chondral damage that increase the risk of future osteoarthritis $(55,56)$.

In this systematic review, no case of fatal complications (grade $V$ ) following the prophylactic surgery on the unaffected hip was recorded among all the 811 children included. The orthopaedic adaptation of the validated Clavien-Dindo classification defines grade IV complications as those leading to potential permanent disability or possibly requiring organ resection (34). According to this definition, we considered AVN of the femoral head and chondrolysis as grade IV complications, for their possible permanent negative impact on hip function, eventually requiring hip arthroplasty. No case of chondrolysis following prophylactic pinning of the unaffected hip is reported in modern studies as far as we know, neither with screw fixation nor with $\mathrm{K}$-wires techniques.

We registered a rate of $0.37 \%$ for AVN of the femoral head, with only 3 patients out of 811 , a very low value that suggests how serious complications are unlikely to occur $(32,40)$. Complications requiring further intervention (grade III), including fractures, deep infections, hardwarerelated pain requiring removal and other unplanned surgery, were experienced by 65 children, with a rate of $8.01 \%(31,36,37,39,40,44,45,46)$. Overall, therefore, a cumulative rate of $8.38 \%$ of children in our review showed the occurrence of major complications. We consider this value to be tolerable, particularly when compared to the high risk of underdiagnosing SCFE in the contralateral hip.

One of the most frequent complications occurred during pin removal (18 patients). On this matter, it should be noticed that the articles included did not specify if hardware was routinely removed in all patients. Hardware retention is still debated because of its possible additional morbidity. In fact, leaving the pins in place may raise the local stress and cause fractures in young adults; furthermore, pinheads may lead to trochanteric bursitis (57). But major issues can be expected in those patients needing total hip replacement years later. In this case, screw removal is mandatory, but a long time passed since pinning may raise surgery duration and complications rate (52).

On the other hand, pins removal, performed as soon as the physis is closed, is reported to be a safe procedure based on a low rate of complications such as post-removal fractures, infection and scar issues (58).

As a matter of fact, the prevalence of bilateral SCFE is variably reported in the literature between 40 and $80 \%$ (9), half of whom develops a contralateral slip in a subsequent period. The vast majority ( $82 \%$ of cases) face this contralateral event within 18 months from the initial slip (11). Modern literature refers that patients with a unilateral SCFE are 2335 times more likely to develop SCFE 
in the contralateral hip when compared to children in the general population (21).

The alternative approach to prophylactic pinning remains rigorous clinical and radiographic monitoring $(59,60)$. Nevertheless, we believe that this approach has some critical points: first of all, the child is exposed to ionizing radiation due to the repeated $\mathrm{X}$-rays, he should undergo at least annually, in order not to miss an acute slip. A recent meta-analysis on paediatric follow-up programmes for spinal disorders demonstrated that years of repeated radiographs and pertaining cumulative radiation dose resulted in elevated rates of cancer, breast cancer and cancer mortality for children with scoliosis in comparison with matched general population (61). A similar consideration can be provided for the X-ray follow-up of the SCFE, which requires close monitoring. Furthermore, another matter of debate is compliance, that is deeply required from parents in order not to miss any early diagnosis of SCFE to their children. The problem is that mild cases of SCFE can remain relatively pain-free, and consequently, parents may be tempted to abandon the prophylactic follow-up, leaving an unrecognized disease untreated (62). Finally, the radiographic follow-up unluckily does not prevent the occurrence of severe slips, which have the worst functional prognosis (63).

Slipped capital femoral epiphysis is a multifactorial disease, whose aetiology is far from being entirely understood. Risk factors that play a role include mechanical force associated with the characteristic morphology of the hip (acetabular or femoral retroversion), endocrinopathies, obesity, chemotherapy, male sex and history of radiation therapy $(4,5,6,64,65)$.

Although some authors suggest that, among children who suffered from SCFE, those at a high risk for contralateral slip should be identified and treated prophylactically $(23,25)$, and others believe that all the children who suffered from unilateral SCFE must be intended as at high risk and therefore advised to undergo prophylactic fixation $(9,24,66)$. Considering in fact that all the risk factors for SCFE are systemic, it is unlikely to differentiate a specific subgroup of patients subject to unilateral slips from another one at risk of bilateral SCFE; therefore, we endorse the latter point of view. The prophylactic fixation of the contralateral healthy hip appears, from the data we collected in the present paper, a safe surgery, with a low risk of complications, justified by the benefit of avoiding the potentially severe consequences of a contralateral undiagnosed slip. Besides, in the benefit-cost ratio analysis, it is vital to include not only biological costs of possible future surgeries but also economic costs. In fact, complications that result in the need for subsequent surgeries require financial expenses for outpatient visits, hospitalization, rehabilitation and possible disability (67). The economic impact of clinical decisions appears to be a trend hot topic in modern health management and deserves specific studies even in the SCFE field.

In addition, the prophylactic surgical technique which results to be the safest is cannulated screws fixation. Although with this technique, we recorded isolated cases of severe complications (AVN, grade IV according to ClavienDindo), these are very low rates: $0.58 \%, 3$ children out of 521 who underwent this procedure in the studies included. Although these complications have not been reported in children treated with Kirschner wires, it is appropriate to remark that the group treated with screws is almost three times larger (521 vs 195 patients) (32, 36, 37, 38, 39, 40, $41,42,43,44)$. Other major complications instead appear far more represented in the group of children treated with Kirschner wires, this is the case of grade III complications (fractures, deep infections, pain to the implant requiring removal and generic other unplanned surgeries). In this review, we registered an overall major complications rate of $17.95 \%$ for the prophylactic fixation with K-wires and $5.37 \%$ for the surgery by means of cannulated screws, testifying to the abovementioned higher security of the latter procedure compared to pinning.

\section{Limitations}

The present review includes a small number of low-quality papers, 14, with a total population of 811 children. The main defect in the quality of the studies included in the current review was the absence of prospective calculation of study size, which was not present in any of the 14 studies.

The sample size therefore cannot be considered fully adequate to evaluate in depth all the variables that influence the decision-making process. Furthermore, the level of evidence of the studies available in the literature is low, as it can be seen from the MINORS scores registered. In fact, only four studies $(32,43,44,45)$ were found to be strongly appropriate in terms of duration of the follow-up period. Consequently to the limited mean follow-up, lateonset complications or further surgeries needed for each child were not possible to be assessed accurately in this investigation. We considered appropriate a follow-up that reached the period of physeal closure, in order to assess the possible disturbance on bone growth. However, it is likely that some complications may occur many years after prophylactic surgery, consequently needing studies with decades of observation to be detected. In addition, there are differences in the definition of some complications, which are subject to interobserver variability. This is especially a concern for minor complications, which were not easy to record for the fact that not all the studies expressly declared these adverse events. 


\section{Conclusions}

The prophylactic fixation of contralateral unaffected hip in paediatric unilateral SCFE is a safe procedure. Although a benefit-cost analysis on this topic has not been published yet, considering the low rate of complications, prophylactic hip fixation is a viable option for patients presenting with unilateral SCFE, to prevent the occurrence of severe hip deformity and avoid future invasive surgeries. It is vital to correctly inform families about the risks associated with the intervention and those associated with the "wait and see' approach. Families who refuse the surgical procedure should be initiated to a close and proper radiographic and clinical follow-up.

In the future, prospective multicentric studies involving experienced paediatric orthopaedic surgeons should be carried out to better guide the decision-making process, further investigating risk factors and complications rate. It will be useful to standardize the surgical procedure and to plan studies following up patients for decades, to better assess the role of fixation and its influence not only on the bone growth processes but also on degenerative phenomena leading to hip osteoarthritis.

Furthermore, modern health management is very interested in the evaluation of the biological and economic costs of clinical choices, so it will be worthwhile to deepen an evaluation of the benefit-cost ratio of prophylactic fixation of the contralateral unaffected hip in SCFE.

\section{ICMJE Conflict of Interest Statement}

The authors declare that there is no conflict of interest that could be perceived as prejudicing the impartiality of the work reported.

\section{Funding Statement}

This work did not receive any specific grant from any funding agency in the public, commercial or not-for-profit sector.

\section{References}

1. Aronsson DD, Loder RT, Breur GJ \& Weinstein SL. Slipped capital femoral epiphysis: current concepts. Journal of the American Academy of Orthopaedic Surgeons 2006 14 666-679. (https://doi.org/10.5435/00124635-200611000-00010)

2. Lehmann CL, Arons RR, Loder RT \& Vitale MG. The epidemiology of slipped capital femoral epiphysis: an update. Journal of Pediatric Orthopedics $2006 \mathbf{2 6} 286-290$. (https://doi.org/10.1097/01.bpo.0000217718.10728.70)

3. Murray AW \& Wilson NI. Changing incidence of slipped capital femoral epiphysis: a relationship with obesity? Journal of Bone and Joint Surgery: British Volume 2008 9092-94. (https://doi.org/10.1302/0301-620X.90B1.19502)

4. Popejoy D, Emara K \& Birch J. Prediction of contralateral slipped capital femoral epiphysis using the modified Oxford bone age score. Journal of Pediatric Orthopedics 2012 32 290-294. (https://doi.org/10.1097/BP0.0b013e3182471eb4)
5. Loder RT, Wittenberg B \& DeSilva G. Slipped capital femoral epiphysis associated with endocrine disorders. Journal of Pediatric Orthopedics 199515 349-356. (https://doi. org/10.1097/01241398-199505000-00018)

6. Loder RT \& Hensinger RN. Slipped capital femoral epiphysis associated with renal failure osteodystrophy. Journal of Pediatric Orthopedics 199717 205-211. (https://doi. org/10.1097/00004694-199703000-00013)

7. Maranho DA, Ferrer MG, Kim YJ, Miller PE \& Novais EN. Predicting risk of contralateral slip in unilateral slipped capital femoral epiphysis: posterior epiphyseal tilt increases and superior epiphyseal extension reduces risk. Journal of Bone and Joint Surgery: American Volume 2019101 209-217. (https://doi.org/10.2106/JBJS.18.00440)

8. Swarup I, Shah R, Gohel S, Baldwin K \& Sankar WN. Predicting subsequent contralateral slipped capital femoral epiphysis: an evidence-based approach. Journal of Children's Orthopaedics 202014 91-97. (https://doi.org/10.1302/1863-2548.14.200012)

9. Hagglund G. The contralateral hip in slipped capital femoral epiphysis. Journal of Pediatric Orthopedics: Part B 19965 158-161. (https://doi.org/10.1097/01202412199605030-00004)

10. Novais EN \& Millis MB. Slipped capital femoral epiphysis: prevalence, pathogenesis, and natural history. Clinical Orthopaedics and Related Research 2012470 3432-3438. (https://doi.org/10.1007/s11999-012-2452-y)

11. Loder RT \& Skopelja EN. The epidemiology and demographics of slipped capital femoral epiphysis. ISRN Orthopedics 20112011 486512. (https://doi. org/10.5402/2011/486512)

12. Loder RT, Aronson DD \& Greenfield ML. The epidemiology of bilateral slipped capital femoral epiphysis. A study of children in Michigan. Journal of Bone and Joint Surgery: American Volume 199375 1141-1147. (https://doi.org/10.2106/00004623-199308000-00003)

13. Hagglund G, Hansson LI, Ordeberg G \& Sandstrom S. Bilaterality in slipped upper femoral epiphysis. Journal of Bone and Joint Surgery: British Volume $1988 \mathbf{7 0}$ 179-181. (https://doi.org/10.1302/0301-620X.70B2.3346283)

14. Abu Amara S, Leroux J \& Lechevallier J. Surgery for slipped capital femoral epiphysis in adolescents. Orthopaedics and Traumatology, Surgery and Research 2014100 (Supplement) S157-S167. (https://doi.org/10.1016/j.otsr.2013.04.015)

15. Aprato A, Conti A, Bertolo F \& Masse A. Slipped capital femoral epiphysis: current management strategies. Orthopedic Research and Reviews 201911 47-54. (https://doi. org/10.2147/ORR.S166735)

16. Strong $\mathbf{M}$, Lejman T, Michno $\mathbf{P}$ \& Sulko J. Fixation of slipped capital femoral epiphyses with unthreaded 2-mm wires. Journal of Pediatric Orthopedics 1996 16 53-55. (https://doi.org/10.1097/00004694-199601000-00010)

17. Seller K, Wild A, Westhoff B, Raab P \& Krauspe R. Clinical outcome after transfixation of the epiphysis with Kirschner wires in unstable slipped capital femoral epiphysis. International Orthopaedics $200630342-347$. (https://doi.org/10.1007/ s00264-006-0110-2)

18. Segal LS, Davidson RS, Robertson Jr WW \& Drummond DS. Growth disturbances of the proximal femur after pinning of juvenile slipped capital femoral epiphysis. Journal of Pediatric Orthopedics 199111 631-637.

19. Jensen HP, Steinke MS, Mikkelsen SS \& Thomsen PB. Hip physiolysis. Bilaterality in 62 cases followed for 20 years. Acta orthopaedica Scandinavica 199061 419-420. (https://doi.org/10.3109/17453679008993553) 
20. Crawford AH. Slipped capital femoral epiphysis. Journal of Bone and Joint Surgery: American Volume 198870 1422-1427.

21. Castro Jr FP, Bennett JT \& Doulens K. Epidemiological perspective on prophylactic pinning in patients with unilateral slipped capital femoral epiphysis. Journal of Pediatric Orthopedics 200020 745-748. (https://doi.org/10.1097/00004694-200011000-00009)

22. Hagglund G. Pinning the slipped and contralateral hips in the treatment of slipped capital femoral epiphysis. Journal of Children's Orthopaedics 201711 110-113. (https://doi. org/10.1302/1863-2548-11-170022)

23. Schultz WR, Weinstein JN, Weinstein SL \& Smith BG. Prophylactic pinning of the contralateral hip in slipped capital femoral epiphysis: evaluation of long-term outcome for the contralateral hip with use of decision analysis. Journal of Bone and Joint Surgery: American Volume 200284 1305-1314. (https://doi.org/10.2106/00004623-200208000-00003)

24. Plotz GM, Prymka M \& Hassenpflug J. The role of prophylactic pinning in the treatment of slipped capital femoral epiphysis - a case report. Acta orthopaedica Scandinavica 199970 631-634. (https://doi.org/10.3109/17453679908997856)

25. Reidy M, Faulkner R, Grupping R, Mayne A, Campbell D \& MacLean J. Slipped capital femoral epiphysis and prophylactic pinning of the contralateral hip: a change in practice. Orthopaedic Proceedings 2018 99-B. (https://doi.org/10.1302/1358992X.2017.18.012)

26. Kroin E, Frank JM, Haughom B \& Kogan M. Two cases of avascular necrosis after prophylactic pinning of the asymptomatic, contralateral femoral head for slipped capital femoral epiphysis: case report and review of the literature. Journal of Pediatric Orthopedics 201535 363-366. (https://doi.org/10.1097/BP0.0000000000000307)

27. Wensaas A, Gunderson RB, Svenningsen S \& Terjesen T. Good long-term outcome of the untreated contralateral hip in unilateral slipped capital femoral epiphysis: forty hips with a mean follow-up of 41 years. Journal of Children's Orthopaedics 20148 367-373. (https://doi.org/10.1007/s11832-014-0611-2)

28. Jerre R, Billing L, Hansson $\mathbf{G}$ \& Wallin J. The contralateral hip in patients primarily treated for unilateral slipped upper femoral epiphysis. Long-term follow-up of 61 hips. Journal of Bone and Joint Surgery: British Volume 1994 76 563-567.

29. Lim YJ, Lam KS \& Lee EH. Review of the management outcome of slipped capital femoral epiphysis and the role of prophylactic contra-lateral pinning re-examined. Annals of the Academy of Medicine 200837 184-187.

30. Moher D, Liberati A, Tetzlaff J, Altman DG \& PRISMA Group. Preferred reporting items for systematic reviews and meta-analyses: the PRISMA statement. Annals of Internal Medicine 2009151 264-269, W64. (https://doi.org/10.7326/0003-4819-151-4200908180-00135)

31. Emery RJ, Todd RC \& Dunn DM. Prophylactic pinning in slipped upper femoral epiphysis. Prevention of complications. Journal of Bone and Joint Surgery: British Volume 199072 217-219. (https://doi.org/10.1302/0301-620X.72B2.2312558)

32. Rostoucher P, Bensahel H, Pennecot GF, Kaewpornsawan K \& Mazda K. Slipped capital femoral epiphysis: evaluation of different modes of treatment. Journal of Pediatric Orthopedics: Part B 19965 96-101. (https://doi.org/10.1097/01202412-199605020-00008)

33. Slim K, Nini E, Forestier D, Kwiatkowski F, Panis Y \& Chipponi J. Methodological index for non-randomized studies (minors): development and validation of a new instrument. ANZ Journal of Surgery 200373 712-716. (https://doi.org/10.1046/ j.1445-2197.2003.02748.x)

34. Dodwell ER, Pathy R, Widmann RF, Green DW, Scher DM, Blanco JS, Doyle SM, Daluiski A \& Sink EL. Reliability of the modified Clavien-Dindo-Sink complication classification system in pediatric orthopaedic surgery. JB and JS Open Access 20183 e0020. (https://doi.org/10.2106/JBJS.0A.18.00020)

35. Dindo D, Demartines N \& Clavien PA. Classification of surgical complications: a new proposal with evaluation in a cohort of 6336 patients and results of a survey. Annals of Surgery 2004240 205-213. (https://doi.org/10.1097/01.sla.0000133083.54934.ae)

36. Herngren B, Stenmarker M, Enskar K \& Hagglund G. Outcomes after slipped capital femoral epiphysis: a population-based study with three-year follow-up. Journal of Children's Orthopaedics 201812 434-443. (doi:. (https://doi.org/10.1302/18632548.12.180067)

37. Bhattacharjee A, Freeman R, Roberts AP \& Kiely NT. Outcome of the unaffected contralateral hip in unilateral slipped capital femoral epiphysis: a report comparing prophylactic fixation with observation. Journal of Pediatric Orthopedics: Part B 201625 454-458. (https://doi.org/10.1097/BPB.0000000000000337)

38. Clement ND, Vats A, Duckworth AD, Gaston MS \& Murray AW. Slipped capital femoral epiphysis: is it worth the risk and cost not to offer prophylactic fixation of the contralateral hip? Bone and Joint Journal 2015 97-B 1428-1434. (https://doi. org/10.1302/0301-620X.97B10.33931)

39. Vlachopoulos L, Huber H, Dierauer S \& Ramseier LE. Persisting growth after prophylactic single-screw epiphysiodesis in upper femoral epiphysis. Journal of Pediatric Orthopedics 201333 816-820. (https://doi.org/10.1097/BP0.0000000000000098)

40. Sankar WN, Novais EN, Lee C, AI-Omari AA, Choi PD \& Shore BJ. What are the risks of prophylactic pinning to prevent contralateral slipped capital femoral epiphysis? Clinical Orthopaedics and Related Research 2013471 2118-2123. (https://doi. org/10.1007/s11999-012-2680-1)

41. Breaud J, Rubio A, Leroux J \& Griffet J. Residual hip growth after pinning of slipped capital femoral epiphysis. Journal of Pediatric Orthopedics: Part B 200918 7-9. (https://doi.org/10.1097/BPB.0b013e3283157ee0)

42. MacLean JG \& Reddy SK. The contralateral slip. An avoidable complication and indication for prophylactic pinning in slipped upper femoral epiphysis. Journal of Bone and Joint Surgery: British Volume 200688 1497-1501. (https://doi.org/10.1302/0301620X.88B11.17523)

43. Dewnany G \& Radford P. Prophylactic contralateral fixation in slipped upper femoral epiphysis: is it safe? Journal of Pediatric Orthopedics: Part B 200514 429-433. (https://doi. org/10.1097/01202412-200511000-00007)

44. Kumm DA, Schmidt J, Eisenburger SH, Rutt J \& Hackenbroch MH. Prophylactic dynamic screw fixation of the asymptomatic hip in slipped capital femoral epiphysis. Journal of Pediatric Orthopedics 199616 249-253. (https://doi. org/10.1097/00004694-199603000-00023)

45. Lerch TD, Novais EN, Schmaranzer F, Ziebarth K, Steppacher SD, Tannast M \& Siebenrock KA. What is the prevalence of cam deformity after prophylactic pinning of the contralateral asymptomatic hip in unilateral slipped capital femoral epiphysis? A 10-year minimum followup study. Clinical Orthopaedics and Related Research 2019477 1111-1122. (https://doi.org/10.1097/CORR.0000000000000592)

46. Woelfle JV, Fraitzl CR, Reichel H \& Nelitz M. The asymptomatic contralateral hip in unilateral slipped capital femoral epiphysis: morbidity of prophylactic fixation. Journal of Pediatric Orthopedics: Part B 201221 226-229. (https://doi.org/10.1097/ BPB.0b013e3283524bae)

47. Seller K, Raab P, Wild A \& Krauspe R. Risk-benefit analysis of prophylactic pinning in slipped capital femoral epiphysis. Journal of Pediatric Orthopedics: Part B 2001 10 192-196. 
48. Pihl M, Sonne-Holm S, Christoffersen JK \& Wong C. Doctor's delay in diagnosis of slipped capital femoral epiphysis. Danish Medical Journal 201461 A4905.

49. Baghdadi YM, Larson AN, Sierra RJ, Peterson HA \& Stans AA. The fate of hips that are not prophylactically pinned after unilateral slipped capital femoral epiphysis. Clinical Orthopaedics and Related Research 2013471 2124-2131. (https://doi.org/10.1007/ s11999-012-2762-0)

50. Lehmann TG, Engesaeter IØ, Laborie LB, Lie SA, Rosendahl K \& Engesaeter LB. Total hip arthroplasty in young adults, with focus on Perthes' disease and slipped capital femoral epiphysis: follow-up of 540 subjects reported to the Norwegian Arthroplasty Register during 1987-2007. Acta Orthopaedica 201283 159-164. (https:// doi.org/10.3109/17453674.2011.641105)

51. Castaneda P, Ponce C, Villareal G \& Vidal C. The natural history of osteoarthritis after a slipped capital femoral epiphysis/the pistol grip deformity. Journal of Pediatric Orthopedics 201333 (Supplement 1) S76-S82. (https://doi.org/10.1097/ BP0.0b013e318277174c)

52. Gallazzi E, Morelli I, Peretti G \& Zagra L. What is the impact of a previous femoral osteotomy on THA? A systematic review. Clinical Orthopaedics and Related Research 2019 477 1176-1187. (https://doi.org/10.1097/CORR.0000000000000659)

53. Luceri F, Morelli I, Sinicato CM, Della Grazia A, Verdoni F, Maffulli N, Peretti GM \& Curci D. Medium-term outcomes of total hip arthroplasty in juvenile patients. Journal of Orthopaedic Surgery and Research 202015 476. (https://doi. org/10.1186/s13018-020-01990-2)

54. Ganz R, Parvizi J, Beck M, Leunig M, Notzli H \& Siebenrock KA. Femoroacetabular impingement: a cause for osteoarthritis of the hip. Clinical Orthopaedics and Related Research 2003417 112-120. (https://doi.org/10.1097/01. blo.0000096804.78689.(2)

55. Leunig M, Casillas MM, Hamlet M, Hersche 0, Nötzli H, Slongo T \& Ganz R. Slipped capital femoral epiphysis: early mechanical damage to the acetabular cartilage by a prominent femoral metaphysis. Acta Orthopaedica Scandinavica 200071 370-375. (https://doi.org/10.1080/000164700317393367)

56. Sink EL, Zaltz I, Heare T \& Dayton M. Acetabular cartilage and labral damage observed during surgical hip dislocation for stable slipped capital femoral epiphysis. Journal of Pediatric Orthopedics 201030 26-30. (https://doi.org/10.1097/BP0.0b013e3181c6b37a)

57. Ilchmann T \& Parsch K. Complications at screw removal in slipped capital femoral epiphysis treated by cannulated titanium screws. Archives of Orthopaedic and Trauma Surgery 2006126 359-363. (https://doi.org/10.1007/s00402-006-0126-5)
58. Pretell-Mazzini J, Rodriguez-Vega V, Munoz-Ledesma J, AndrésEsteban EM, Marti-Ciruelos R, González-López JL \& Curto-De la Mano A. Complications and associated risk factors at screw removal in slipped capital femoral epiphysis treated by cannulated stainless steel screws. Journal of Children's Orthopaedics 2012 6 285-289. (https://doi.org/10.1007/s11832-012-0425-z)

59. Koenig KM, Thomson JD, Anderson KL \& Carney BT. Does skeletal maturity predict sequential contralateral involvement after fixation of slipped capital femoral epiphysis? Journal of Pediatric Orthopedics 200727 796-800. (https://doi.org/10.1097/ BP0.0b013e3181558bd9)

60. Riad J, Bajelidze G \& Gabos PG. Bilateral slipped capital femoral epiphysis: predictive factors for contralateral slip. Journal of Pediatric Orthopedics 200727 411-414. (https://doi.org/10.1097/01.bpb.0000271325.33739.86)

61. Luan FJ, Wan Y, Mak KC, Ma CJ \& Wang HQ. Cancer and mortality risks of patients with scoliosis from radiation exposure: a systematic review and metaanalysis. European Spine Journal 202029 3123-3134. (https://doi.org/10.1007/s00586020-06573-7)

62. Uvodich M, Schwend R, Stevanovic 0, Wurster W, Leamon J \& Hermanson A. Patterns of pain in adolescents with slipped capital femoral epiphysis. Journal of Pediatrics 2019206 184.e1-189.e1. (https://doi.org/10.1016/j.jpeds.2018.10.050)

63. Allen MM \& Rosenfeld SB. Treatment for post-slipped capital femoral epiphysis deformity. Orthopedic Clinics of North America 202051 37-53. (https://doi.org/10.1016/j. ocl.2019.08.008)

64. Pritchett JW \& Perdue KD. Mechanical factors in slipped capital femoral epiphysis. Journal of Pediatric Orthopedics $1988 \mathbf{8}$ 385-388. (https://doi.org/10.1097/01241398198807000-00001)

65. Gebhart JJ, Bohl MS, Weinberg DS, Cooperman DR \& Liu RW. Pelvic incidence and acetabular version in slipped capital femoral epiphysis. Journal of Pediatric Orthopedics 201535 565-570. (https://doi.org/10.1097/BP0.0000000000000342)

66. Hurley JM, Betz RR, Loder RT, Davidson RS, Alburger PD \& Steel HH. Slipped capital femoral epiphysis. The prevalence of late contralateral slip. Journal of Bone and Joint Surgery: American Volume 199678 226-230. (https://doi.org/10.2106/00004623199602000-00009)

67. Buttner M, Mayer AM, Buchler B, Betz U, Drees P \& Susanne S. Economic analyses of fast-track total hip and knee arthroplasty: a systematic review. European Journal of Orthopaedic Surgery and Traumatology 202030 67-74. (https://doi.org/10.1007/ s00590-019-02540-1) 